thing whatever to do with the whole matter. If your reasons are honorable, for Heaven's sake out with them! "If not a settled policy" we may be able to find more than nine years of history and two competing publications to prove it. I by no means intend that the principles at issue shall be allowed to be made confused by any such alarums to distract the enemy's attention. In the present instance your contemptible charge that I have no higher motive in this whole matter than to advertise a book of which $\mathrm{I}$ am one of 28 editors, and that $\mathrm{I}$ allow my publisher to use my editoral utterances purely as his advertising medium, is-well! What may a gentleman say to such an insult? I am perfectly willing to leave such impertinence to be answered by the three publishers with whom I have had close business relations and with the readers of the Medical News. Some men, my dear sir, are very prone to ascribe low motives to others, but the reason is proverbially known. Oh, no, the instances are too few, but they exist, of editors who are not the jumping-jacks of their publishers. No publisher could have forced into my editorial columns such an editorial as this of yours under discussion. Mr. Saunders had no hand in the writing of that circular, was not consulted about it, knew nothing about when, or where it was mimeographed, mailed, etc. It was solely and wholly my own work. He has no more knowledge concerning this letter. Instead of all this shameless trying to turn the issue and of all these blank denials, it would be far more to the point if you would explain to your contributors how it is not against their interests to refuse to allow their gratuitously given articles to be abstracted and illustrated in the only two (not in only one as you say) earnest attempts that have been made to get up in English something comparable to the immensely serviceable and necessary German Jahrbücher and epitomes of medical progress. Also please explain how it is your action does not prevent the dissemination of medical literature. If it does not do so the necessary inference is that your two journals in your own estimation contain nothing worthy of being thus used in a résumé of medical science and progress : Lastly will you not explain to the sixty-six departmental editors of Dr. Sajous' Annual, and to the twenty-seven gentlemen connected with the American Year-Book in what way these two publications are disreputable, or non-reputable? Are they not quite as reputable as your publisher's similar Handbook, etc., and his pirated whole books of our English colleagues republished without their consent, and sometimes against their command and to their financial loss, as in those instances when other American publishers would have paid them for the right to reprint had it been possible to guard against the American pirate?

I reserve a little clarifying discussion of your publisher's position until a later date. Cordially yours,

119 S. 17th Street. Geo. M. Gould.

\section{Medical Ethics.}

Wichita, Kan., Feb. 10, 1897.

To the Editor:-I am informed, I think creditably, that one or more specialists in the west are offering as inducement to the profession for their patronage, to divide fees. In one instance there is a verbal agreement to give 25 per cent. I would like the Journal's opinion of the practice. To me it savors much of bribery, both parties sharing in the guilt, the specialists in large cities, like Chicago for instance offering the profession such inducements.

I might be tempted to do likewise if it was a case of bread and butter, but it seems to me my financial condition must be much straitened before I would even listen to the tempter. Perhaps I am wrong! Perhaps in the struggle for fame and fortune my patronage ought to go to the highest bidder but it seems to me I ought to be influenced entirely in dispensing patronage by fitness and merit. I do not care to have my name used in print in this connection. I should of course lay myself liable to the charge that I am influenced by jealous motives which is not the case. Should you decide to answer privately or through the medium of the Jounnal, which I highly prize, I shall be pleased. I am fraternally yours, M.D.

ANswer: The offering or giving any portion of a fee to one who procures cases for another is the worst possible means of obtaining practice. Both parties are equally guilty of a breach of honorable dealing. Such conduct is on a par with the acceptance by a physician of a percentage from an apothecary to whom he directs his prescriptions to be taken. So patent did this appear to those who framed the Code of Ethics that they did not deem it necessary to insert any clause in regard to it.

Philadelphia, Feb. 15, 1897.

W. B. Atkinson, M.D.

\section{PUBLIC HEALTH.}

Invidious Discrimination Against the Profession in the Proposed Charter of the Greater New York.-Dr. Z. T. Emery, in his capacity of Commissioner of Health of Brooklyn, has addressed a communication to the charter commission regarding an undesirable discrimination proposed to be made against medical men by making it impossible for any one of them, however competent he may be, from becoming the head of the department of health. The text of the section of the now pending charter relating to the organization of the department of health reads as follows:

Section 1.-There shall be a health department whereof the head shall be the board of health. Said board shall consist of the president of the board of police, the health officer of the port and two officers to be called commissioners of health, one of whom shall have been a practicing physician for not less than ten years preceding his appointment. The commissioner of health who is not a physician shall be the president of the board and shall be so designated in his appointment. The commissioners of health shall, unless sooner removed, respectively hold their offices for four years, and until their successors shall be respectively appointed and have qualified, except the first commissioners, of whom the president of the board of health shall be appointed for two years, and the other commissioner for four years, and until their successors are respectively appointed and have qualified.

The remarks of Dr. Emery are, in part, as follow: "The first section provides that the head of the health department shall be a board, to consist of the president of the board of police and the health officer of the port and two officers to be called commissioners of health, one of whom shall have been a practicing physician for not less than ten years preceding his appointment. The commissioner of health who is not a physician shall be the president of the board and shall be so designated in his appointment. I desire to make emphatic protest; first, against making the head of the department of health a board composed of four members ; and second, against the discrimination which is here made against the members of the medical profession by the provision that under no circumstances shall a physician become the president of such board. It is respectfully submitted to the commission that the head of the department of health should consist of one member, for the reason that in addition to the ordinary routine work of obtaining compliance with the laws and ordinances relating to public health, the duties of the health department consist largely in dealing with the emergencies which continually arise, affecting the welfare and lives of considerable portions of the community, and it is my observation that more prompt and efficient action can be obtained by a health department having a single head. Such emergencies demand immediate decision and action and do not admit of divided opinion and judgment, nor can they wait for a meeting of the board and an adjustment of differences of opinion. Further, $I$ believe that 